\title{
Health Emergency and Disaster Risk Management (Health- EDRM) in Remote Ethnic Minority Areas of Rural China: The Case of a Flood-Prone Village in Sichuan
}

\author{
Emily Ying Yang Chan ${ }^{1,2,3} \cdot$ Chunlan Guo ${ }^{1}$ Poyi Lee $^{1} \cdot$ Sida Liu ${ }^{1}$. \\ Carman Ka Man Mark ${ }^{1}$
}

Published online: 11 May 2017

(c) The Author(s) 2017. This article is an open access publication

\begin{abstract}
Remote, rural ethnic-minority communities face greater disaster-related public health risks due to their lack of resources and limited access to health care. The Ethnic Minority Health Project (EMHP) was initiated in 2009 to work with remote, disaster-prone ethnic-minority villages that live in extreme poverty. One of the project's aims is to develop and evaluate bottom-up health risk reduction efforts in emergency and disaster risk management (HealthEDRM). This article shares project updates and describes field intervention results from the Yi ethnic community of Hongyan village in China's Sichuan Province, an area that experiences recurrent floods. It was found that $64 \%$ of the village respondents had never considered any form of disaster preparation, even with the recurrent flood risks. Health intervention participants showed sustained knowledge retention and were nine times more likely to know the correct composition of oral rehydration solution (ORS) after the intervention. Participants also retained the improved knowledge on ORS and disaster preparedness kit ownership 12 months after the intervention.
\end{abstract}

Keywords Disaster preparedness kit · Disaster risk reduction $\cdot$ Ethnic minority $\cdot$ Health emergency and

Emily Ying Yang Chan

emily.chan@cuhk.edu.hk

1 Collaborating Centre for Oxford University and CUHK for Disaster and Medical Humanitarian Response (CCOUC), The Jockey Club School of Public Health and Primary Care, The Chinese University of Hong Kong, Hong Kong, China

2 Nuffield Department of Medicine, University of Oxford, Oxford OX1 2JD, UK

3 FXB Centre of Health and Human Rights, Harvard University, Cambridge, MA 02138, USA disaster risk management (Health-EDRM) - Oral rehydration solution $\cdot$ Recurrent floods $\cdot$ Rural China

\section{Introduction}

In remote, resource-poor rural communities, bottom-up (rather than top-down) disaster preparedness efforts can build emergency resilience. Bottom-up preparedness is of particular importance in remote regions because timely external assistance in the event of disasters is often absent. In 2009, the Collaborating Centre for Oxford University and CUHK for Disaster and Medical Humanitarian Response (CCOUC) established the Ethnic Minority Health Project (EMHP). One of the aims of the EMHP is to develop and evaluate bottom-up health and emergency and disaster risk management (HealthEDRM) for vulnerable populations in remote areas in Asia. In China, the EMHP project team has established 14 project village sites across nine provinces based on four selection criteria-geographical remoteness, ethnic minority representation, economic vulnerability (living on under USD 1.25/ person/day), and disaster proneness. The project has an outreach area that encompasses more than 17,000 villagers in communities of the northwest Ancient Silk Road, the southwest Ancient Tea Horse Road, the southwest border region adjacent to the Golden Triangle, the Tibetan Plateau, the Loess Plateau of the Yellow River basin, the source area of the Yangtze River, and the northeast "Rust Belt" (Fig. 1).

\section{Study Context: Hongyan Village in Sichuan Province}

Hongyan village is an ethnic minority-based community that is $91 \%$ Yi ethnicity (1\% Han Chinese, $8 \%$ other ethnic groups). The village is an agricultural, non-migrant 
Fig. 1 Project sites of the CCOUC Ethnic Minority Health Project in China (as of April 2017)

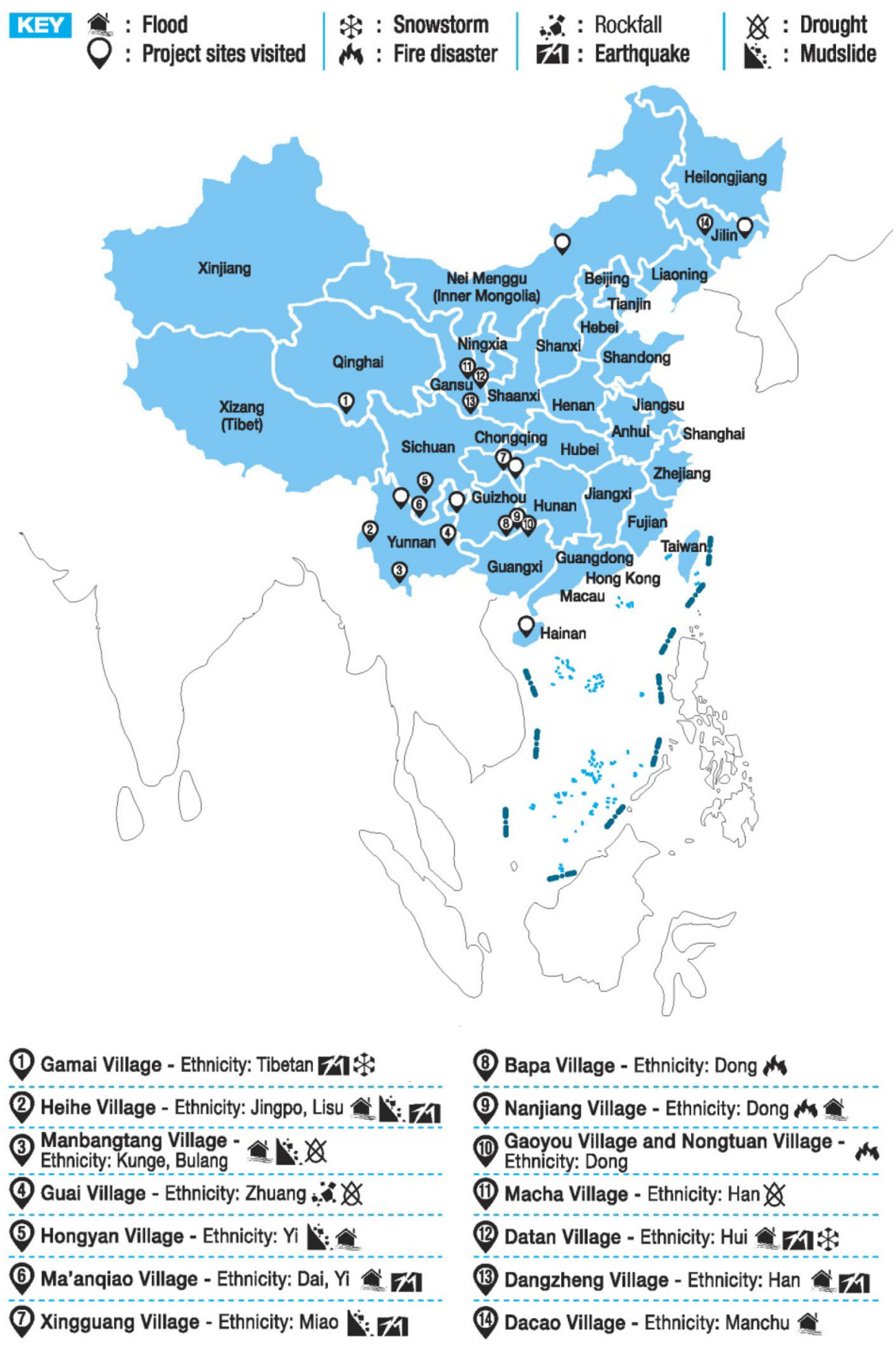

based village composed of 217 households and 826 residents. It is one of the 169 villages in Xide County, in the Liangshan Yi Autonomous Prefecture that is situated in the southern area of Sichuan Province. In 2014, the majority of families lived under the United Nations international extreme poverty line (USD 1.25 per day during the study period), with an annual household income around USD 100-120 in 2014.
A major flood occurred on 31 August 2012 in Xide County where Hongyan village is located. The flood caused massive local damage with an estimated total economic loss of RMB 3.16 billion Yuan in the county (equivalent to the local government's budget for 30 years) (Liu 2012). Due to geographic remoteness and infrastructural collapse (Fig. 2), the Hongyan villagers were isolated from the outside world for more than 2 months. 
Fig. 2 Isolation of Hongyan village, Xide County, Sichuan Province, China after the 31 August 2012 flood. The flood collapsed the bridge and disconnected the villagers from the outside world for more than 2 months. Source Photograph by Emily Y.Y. Chan and Sida Liu, October 2012

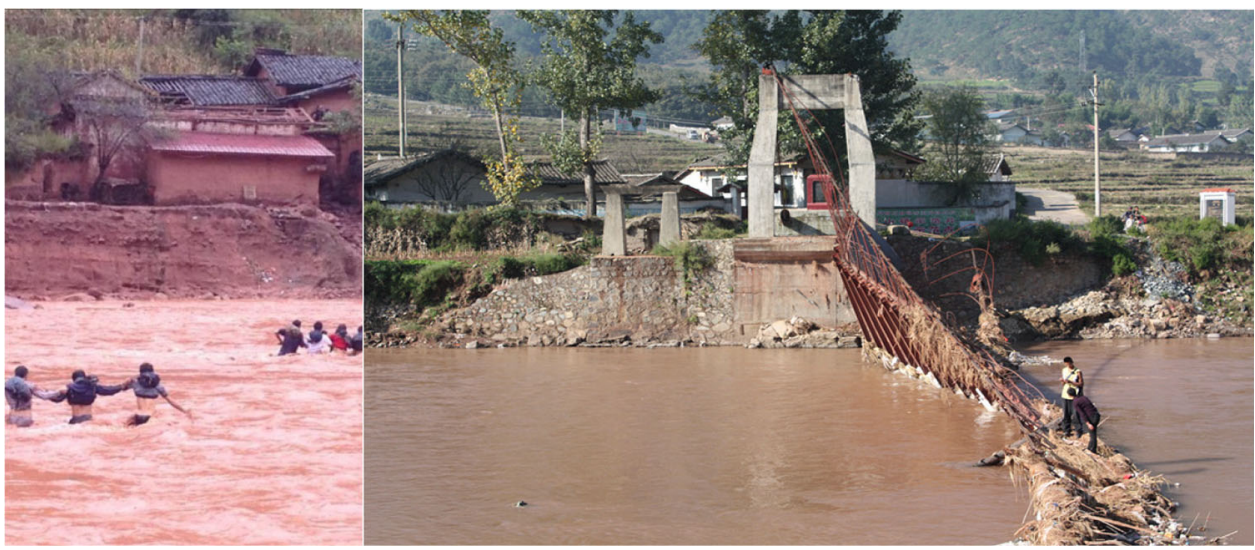

\section{Project Description and Evaluation}

Through the support of the China Ministry of Civil Affairs and recommendation by the $\mathrm{Wu} \mathrm{Zhi}$ Qiao Charitable Foundation, a 3-year project, from 2012 to 2015, was established in Hongyan village after the August 2012 flood. This article summarizes some of the key findings on the effectiveness of a bottom-up training intervention conducted in 2014.

Baseline and post-intervention data were collected through cross-sectional interviewer-administered questionnaire surveys in 2012, 2014, and 2015. Qualitative data were collected through key informant interviews and focus groups in 2012 and 2015. Verbal consent was obtained for all study participants. While all village residents were invited to join the interventions, 54 households ( $25 \%$ of the village community) were selected randomly from the official household register list to participate in periodic cross-sectional household-based surveys to evaluate the project's impact.

Based on the 2012 needs assessment findings, health and disaster risk reduction promotion interventions, each lasting about 30-45 min, were planned and implemented 28 March-1 April 2014. Although diarrhea and water- and vector-borne diseases are preventable post-disaster health problems, these risks are often neglected by remote communities in western China (Gustafsson and Ding 2009; WHO 2014; Chan 2017). Community training sessions on general health risk awareness (the importance of washing hands, for example), household disaster kit preparation, and the preparation of a homemade oral rehydration solution (ORS) were conducted. Field interventions included education in general water safety and sanitation, indoor environment maintenance, waste management, and other health behaviors. Low-cost and locally accessible items according to the five essential health needs (water/sanitation, food/ nutrition, non-food items including shelter/clothing, health care, and information/communication) were included in disaster preparedness kit preparation (Bolton 2006; Chan 2017). Due to the low literacy rate, educational interventions mainly relied on graphical information and dramatized presentations. Validated questionnaires (30 questions) were administered to evaluate intervention effectiveness by comparing the results before and immediately after the interventions. This was followed with an evaluation of the overall project impact 12 months later, in March 2015.

All data were double entered and cleaned by trained staff. Descriptive statistics were generated and group differences were analyzed using Chi square tests $(\alpha=0.05)$. All statistical analyses were conducted with SPSS version 21.0. Ethics approval was obtained from the sponsoring university.

\section{Key Program Findings}

Despite the recurrent flood threats, up to $72.5 \%$ of the village respondents did not have any form of disaster preparedness before the August 2012 flood. Health intervention participants showed sustained knowledge retention. They were nine times more likely to know the correct composition of oral rehydration solution, and retained the improved knowledge on ORS and disaster preparedness kit ownership 12 months after the intervention.

\subsection{The Sample Population}

The sociodemographic characteristics of the 2014 study sample, in comparison with those of Sichuan Province and the latest available data from China, are shown in Table 1. Most of the sociodemographic characteristics of Hongyan village are comparable to those of Sichuan Province and national data. Major differences were observed in literacy rate and occupation between the Han majority in Sichuan Province and China and the Yi minority in Hongyan village. 
Table 1 Comparison of sociodemographic characteristics of Hongyan, Sichuan, and China

\begin{tabular}{llll}
\hline & Hongyan village $2014^{\mathrm{a}}$ & Sichuan Province 2014 & China $^{\mathrm{c}}$ \\
\hline Male to female ratio & $1: 0.97$ & $1: 1.06$ & $1: 0.95(2015)$ \\
Average age & 42.2 & 37.4 & $37.1(2016)$ \\
Yi ethnicity & $91 \%$ & $3.3 \%(2010)$ & $0.7 \%(2010)$ \\
Han ethnicity & $1.0 \%$ & $93.9 \%(2010)$ & $91.5 \%(2010)$ \\
Agricultural sector occupation & $86.0 \%$ & $41.5 \%$ & $28.3 \%(2015)$ \\
Educational attainment & & & $5.4 \%(2014)$ \\
Non-literate & $55.0 \%$ & $5.4 \%$ & $26.2 \%(2014)$ \\
Primary school & $16.0 \%$ & $34.6 \%$ & $40.2 \%(2014)$ \\
Junior high & $6.0 \%$ & $34.9 \%$ & $16.7 \%(2014)$ \\
Senior high & $2.0 \%$ & $11.3 \%$ & $11.5 \%(2014)$ \\
Tertiary education & $0 \%$ & $6.7 \%$ & $3.9(2012)$ \\
Mean household size & & 3.86 & $2.9(2012)$ \\
Rural & 4.23 & 2.92 & \\
Urban & N/A & & \\
\hline
\end{tabular}

a The 54 households of the tracking cohort among the 217 households

b Sichuan provincial data (SBOS 2014)

${ }^{c}$ China national data (NBOSC 2010, 2012, 2014, 2015); World Factbook (2016)

\subsection{Disaster Preparedness and Health Impacts of the August 2012 Flood}

Of the village respondents, $80 \%$ reported that they had experienced a disaster in the previous 3 years. ${ }^{1}$ However, $72.5 \%$ of the village respondents did not have any disaster preparation before the August 2012 flood, and 64\% had never thought about disaster preparedness at all. Barriers to not preparing were the lack of knowledge/awareness of how to prepare a household disaster kit, the formulation of ORS, the purpose of ORS, the disaster implications associated with the villagers' living environment, and everyday health behaviors (with respect to, for example, water procurement, food safety management (for example, storage and preparation), sanitation and hygiene practices, and control of vector-borne diseases).

No flood-related casualty was reported among these sample households, but $45 \%$ had one family member who experienced at least one episode of diarrhea within the first month after the flood. Moreover, children were the vulnerable group who reported more water, food, and vectorborne (mosquitoes) health issues than the other age groups. Outside communication, information, and support were interrupted for an average 7-14 days. Village respondents reported spending an average of 62 days in temporary shelters, and $86 \%$ of sample households reported the loss of all cash crops during the August 2012 floods.

\footnotetext{
${ }^{1}$ Data were acquired from the 2014 household survey in Hongyan village (CCOUC 2014).
}

\subsection{Evaluation of Intervention Effectiveness}

Of the 217 households, $47 \%(n=102)$ participated in the intervention training sessions and completed the pre- and post-intervention questionnaires in 2014. The final valid sample size in 2014 was 100 .

\subsubsection{Disaster Preparedness Kit}

Over $80 \%$ of the participants regarded disaster preparedness kits as necessary, but less than half knew what items should be included. After the intervention, the knowledge of essential items that should be included in a disaster preparedness kit showed statistically significant changesmost of the necessary items showed a significant increase, while most of the unnecessary items showed a significant decrease (Table 2).

\subsubsection{Oral Rehydration Solution (ORS) Preparation}

Pre-intervention, approximately half of the participating households reported to have some knowledge associated with dehydration, but only $13 \%$ reported being able to prepare a homemade oral rehydration solution. The knowledge of ORS composition improved nine-fold after the intervention (Table 3). Results from the 12-months follow-up showed significant differences in knowledge of ORS preparation and reported ownership of disaster preparedness kits between those who had attended the 2014 intervention and those who had not attended (Table 4). One pattern that is unexpected on the knowledge and attitude change between participants and 
Table 2 List of items covered in the 2014 pre- and post-intervention household questionnaire on the content of a disaster preparedness kit $(n=100)$ in Hongyan village (necessary items in bold)

\begin{tabular}{|c|c|c|c|c|}
\hline Item & & Pre-intervention $(\%)$ & Post-intervention (\%) & $\%$ Change \\
\hline \multirow[t]{3}{*}{ Information and communication } & Whistle & 50 & 73 & $+23 *$ \\
\hline & Torch & 73 & 81 & +8 \\
\hline & ID card & 62 & 79 & $+17 *$ \\
\hline \multirow[t]{3}{*}{ Non-food items including shelter and clothing } & Multiple-purpose knife & 16 & 29 & $+13^{*}$ \\
\hline & Emergency blanket & 36 & 52 & $+16^{*}$ \\
\hline & Umbrella & 48 & 33 & $-15^{*}$ \\
\hline \multirow[t]{2}{*}{ Health care } & Medication box & 42 & 61 & $+19 *$ \\
\hline & Long-term medication & 43 & 56 & $+13^{*}$ \\
\hline \multirow[t]{2}{*}{ Food and nutrition } & Fire-starter & 40 & 74 & $+34 *$ \\
\hline & Rice cooker & 43 & 26 & $-17 *$ \\
\hline Water and sanitation & Water & 47 & 47 & 0 \\
\hline \multirow[t]{2}{*}{ Others } & Watch & 39 & 23 & $-16^{*}$ \\
\hline & Farming tools & 24 & 22 & -2 \\
\hline
\end{tabular}

$N=102$, Valid questionnaires $n=100$. Items included are adapted from the core principles of maintaining health in the SPHERE standard (SPHERE 2011) and in Chan (2017)

The items listed here are not exhaustive. These items are those that were included in the questionnaire testing the knowledge level after the intervention. For the full content of the disaster preparedness kit, please refer to the Training Manual on Health and Disaster Preparedness in Rural China available at http://www.ccouc.org

* Chi square $p$ value $<0.05$

Table 3 Results of the 2014 pre- and post-intervention household questionnaire on ORS-related knowledge $(n=100)$ in Hongyan village

\begin{tabular}{lclc}
\hline & Pre-intervention $(\%)$ & Immediately post-intervention $(\%)$ & $\%$ Change \\
\hline Preparation of ORS & 13 & 76 & 74 \\
How to prepare ORS & 8 & 47 \\
Composition of ORS & 44 & & $+63^{*}$ \\
Regard ORS preparation as difficult & & 78 & $+66^{*}$ \\
Knowledge of ORS health benefits & 53 & 73 & +3 \\
Agree diarrhea causes dehydration & 40 & $+25^{*}$ \\
Agree dehydration leads to death & & & $+33^{*}$ \\
\hline
\end{tabular}

$N=102$, Valid questionnaires $n=100$

* Chi square $p$-value $<0.05$

non-participants is on the confidence of disaster kit preparation. Non-participants (68\%), lacking awareness on the content of the disaster kit, are reported to be more confident than participants (55\%). This higher self-reported confidence of non-participants was over-rated since only $31 \%$ of them have a disaster kit at home.

\subsubsection{Health Risk Management}

While gastroenteritis was the most commonly reported and preventable health problem (accounts for $80 \%$ of the health care-seeking behavior in the village), $40 \%$ of the responding villagers reported no regular habit of handwashing in spite of the stable access to water sources
(CCOUC 2014). Although the handwashing intervention did not show a statistically significant effect, more respondents reported handwashing before meals (Table 5). In particular, the 2012 data showed that the diarrhea prevalence was $45 \%$ while $54.6 \%$ of respondents drank water without any treatment. A surge of diarrhea cases in the 2012 survey may be due to poor hygiene after the flood. Meanwhile, the contaminated water supply after the flood might explain why fewer respondents drank untreated water. In 2015, the data indicated that self-reported diarrhea cases decreased to $35.6 \%$ and a significant rise of reports on drinking water without any treatment (81.4\%). Overall, the 2015 data reflects the usual scenario of both the diarrhea pattern and water treatment in the village. 
Table 4 Knowledge and attitude change 12 months post-intervention (2015), comparing the 2014 health intervention participants and nonparticipants $(n=59)$

\begin{tabular}{|c|c|c|}
\hline & $\begin{array}{l}\text { Participants } \\
\% \text { Correct }\end{array}$ & $\begin{array}{l}\text { Non-participants } \\
\% \text { Correct }\end{array}$ \\
\hline Know the correct composition of ORS & $25 \%(10)$ & $0 \%(0)^{*}$ \\
\hline \multirow[t]{2}{*}{ Know the correct proportion of ORS components } & $5 \%(2)$ & $0 \%(0)^{*}$ \\
\hline & $\%$ Agree & $\%$ Agree \\
\hline Feel confident when making ORS & $30 \%(12)$ & $11 \%(2)^{*}$ \\
\hline Feel confident when preparing disaster kit & $55 \%(22)$ & $68 \%(13)^{*}$ \\
\hline Have a disaster kit at home (Ownership) & $60 \%(24)$ & $31 \%(6)^{*}$ \\
\hline Feel that it is necessary to take a disaster kit in the event of a disaster & $85 \%$ (34) & $79 \%(15)^{*}$ \\
\hline
\end{tabular}

Among the 59 respondents, 40 were participants in 2014 health intervention and 19 were non-participants

* Chi square $p$-value $<0.05$

Table 5 Comparison of various self-reported health-related beliefs and practices in Hongyan village

\begin{tabular}{|c|c|c|c|c|}
\hline Items & Health risk-mitigating practices & $\begin{array}{l}2012 \\
(n=54)\end{array}$ & $\begin{array}{l}2015(n=59) \\
(\%)\end{array}$ & $\begin{array}{l}\% \\
\text { Change }\end{array}$ \\
\hline \multirow{2}{*}{$\begin{array}{l}\text { Water and } \\
\text { sanitation }\end{array}$} & Obtained from pipe water & NA & 69.5 & NA \\
\hline & Drink water without any treatment & $54.6 \%$ & 81.4 & $+26.8 \% *$ \\
\hline \multirow[t]{3}{*}{ Handwashing $^{\mathrm{a}}$} & Before eating & $56.6 \%$ & 66.1 & $+9.5 \%$ \\
\hline & After using toilet & $54.7 \%$ & 52.5 & $-2.2 \%$ \\
\hline & Soap or detergent use observed when handwashing & NA & 23.7 & NA \\
\hline \multirow[t]{2}{*}{ Waste management } & Recycling of plastic bottles & $49.2 \%$ & 50.8 & $+1.6 \%$ \\
\hline & Dump on land & $53.7 \%$ & 50.8 & $-2.9 \%$ \\
\hline \multirow{2}{*}{$\begin{array}{l}\text { Disaster } \\
\quad \text { preparedness }\end{array}$} & Think preparing a disaster kit is important in case of a disaster & $58.0 \%$ & 92.5 & $+34.5^{*}$ \\
\hline & $\begin{array}{l}\text { Think family has the ability to protect health and safety when disaster comes } \\
\text { in future }\end{array}$ & $42.0 \%$ & 67.8 & $+25.8 \% *$ \\
\hline $\mathrm{ORS}^{\mathrm{a}}$ & Know how to make ORS & 9.5 & 40.7 & $31.2 \% *$ \\
\hline
\end{tabular}

Data in 2012 were obtained 4-month after the August 2012 flood whereas the data in 2015 were obtained at the evaluation phase

* Chi square $p$-value $<0.05$

${ }^{a}$ Indicates the topics of disaster and health risk reduction intervention raised by the project team in 2014

\section{Discussion and Lessons Identified}

Since 2000, China has had the highest number of floods (UNISDR 2015) in the world. Though many Hongyan villagers had experienced devastating economic losses from previous floods, disaster risk perceptions, health risk awareness, and disaster preparedness were remarkably low. These findings are largely consistent with other studies conducted in similar socioeconomic contexts in China (Chan et al. 2014).

Extreme poverty remains a strong barrier that prevents resource deficit communities from acquiring the materials needed for the preparation of disaster preparedness kits. But the bottom-up health risk reduction intervention demonstrated its effectiveness to enhance community disaster preparedness. For all targeted disaster health risk reduction interventions, sustained knowledge enhancement (12 months post-intervention) was demonstrated. Although
ORS preparation might be an important low-cost, readily available solution to support disaster health risk reduction, especially for children (Molla et al. 1989; Sillah et al. 2013), the knowledge and use of ORS remain low among rural communities in the world. There was generally limited awareness of ORS as a potential supportive self-help treatment in rural communities.

Despite the effectiveness of the intervention, certain limitations are recognized. First, although an overall effect was observed, it was difficult to differentiate the effective components and messages within the intervention. Complex community intervention trials should be attempted in future studies (Hohmann and Shear 2002; Grant 2013). The decrease of self-reported diarrhea cases in 2015 (12-month post-intervention) from 2012 (4-month post-flood) in the community should be interpreted with caution as there might be a general surge of diarrhea cases immediately after flooding. Nevertheless, a focus group 
discussion found that participants regarded handwashing habit education as the main reason the overall diarrhea prevalence decreased during the 12 months after the intervention. Second, most field-based interventions promoted by nongovernment or government groups might not be grounded on theoretical models, which makes evaluation challenging. For this project, the precaution adoption process model (Jassempour et al. 2014) proved valuable to support the planning of the health intervention to train up disaster preparedness. Language barriers and low education levels may contribute to any reporting and recall bias.

The long-term impact sustainability beyond 12 months and the results of other risk reduction interventions (for example, water boiling, food safety, and vector control) will be evaluated in future reports. This article aims to communicate that low-cost interventions still hold their value in poor and disaster-prone rural communities.

\section{Conclusion}

The findings indicate that in remote and resource-poor areas, health risk awareness and disaster preparedness are limited even though these communities are frequently exposed to recurrent disasters, such as floods. Areas with recurrent disasters will need to strengthen their bottom-up resilience in Health-EDRM to improve preparedness, response capacity, and overall health outcomes. This project progress report highlights that a low-cost health educational approach remains an important bottom-up model to empower remote rural communities to build resilience and reduce health risks associated with disasters and health emergencies. Future studies will be necessary to understand the health emergency and disaster risks and to ascertain the optimal strategies for improving health and reducing disaster risks in remote communities. For more information related to this project or CCOUC, please visit: http://www.ccouc.org.

\footnotetext{
Acknowledgements This project was funded by the CCOUC field research fund, the Chow Tai Fook Charitable Foundation, the I-CARE Programme (The Chinese University of Hong Kong), and the $\mathrm{Wu}$ Zhi Qiao Charitable Foundation. The authors express special appreciation to Prof. Edward Ng, Dr. Tony Yung, Mr. Darren Nash, Ms. Crystal Ying-Jia Zhu, Prof. Kevin Hung, Mr. Zhe Huang, Mr. C.S. Wong, Ms. Carol Wong, Ms. Gloria Chan, Dr. Holly Lam, Prof. Jennifer Leaning, Dr. Elizabeth Newnham, and Prof. Jean Kim for their assistance in the data collection and their intellectual and collaborative support throughout the project development process.
}

Open Access This article is distributed under the terms of the Creative Commons Attribution 4.0 International License (http://crea tivecommons.org/licenses/by/4.0/), which permits unrestricted use, distribution, and reproduction in any medium, provided you give appropriate credit to the original author(s) and the source, provide a link to the Creative Commons license, and indicate if changes were made.

\section{References}

Bolton, P. 2006. Managing disasters and other public health crises. In Oxford handbook of public health practice, 2nd edn., ed. D. Pencheon, C. Guest, D. Melzer, and J.A.M. Gray, 249-256. New York: Oxford University Press.

CCOUC (Collaborating Centre for Oxford University and CUHK for Disaster and Medical Humanitarian Response). 2014. The ethnic minority health project: Trip report for Hongyan, Sichuan. Hong Kong: CCOUC.

Chan, E.Y.Y. 2017. Public health humanitarian responses to natural disasters. New York: Routledge.

Chan, E.Y.Y., J. H. Kim, C. Lin, E.Y.L. Cheung, and P.Y. Lee. 2014. Is previous disaster experience a good predictor for disaster preparedness in extreme poverty households in remote muslim minority based community in China? Journal of Immigrant and Minority Health 16(3): 466-472.

Grant, A., T. Shaun, D. Tobias, F. Robbie, and G. Bruce. 2013. Process evaluations for cluster-randomised trials of complex interventions: A proposed framework for design and reporting. Trials 14: Article 15

Gustafsson, B., and S. Ding. 2009. Villages where China's ethnic minorities live. China Economic Review 20(2): 193-207.

Hohmann, A.A., and M.K. Shear. 2002. Community-based intervention research: Coping with the 'noise' of real life in study design. American Journal of Psychiatry 159(2): 201-207.

Jassempour, K., K.K. Shirazi, M. Fararooei, M. Shams, and A.R. Shirazi. 2014. The impact of educational intervention for providing disaster survival kit: Applying precaution adoption process model. International Journal of Disaster Risk Reduction 10: $374-380$.

Liu, C. 2012. Xide in Sichuan is facing a huge shortage of funds and the poverty-stricken county encounters major difficulties in reconstruction after the flood disaster. Huaxi Dushi Newspaper. http://politics.people.com.cn/n/2012/1227/c14562-20032572.html. Accessed 13 Apr 2017 (in Chinese).

Molla, A.M., S.K. Nath, and M. Khatun. 1989. Food-based oral rehydration salt solution for acute childhood diarrhoea. The Lancet 334(8660): 429-431.

NBOSC (National Bureau of Statistics of China). 2010. 2010 Population census. http://www.stats.gov.cn/tjsj/pcsj/rkpc/6rp/ indexch.htm. Accessed 27 Apr 2017.

NBOSC (National Bureau of Statistics of China). 2012. National data. http://data.stats.gov.cn/easyquery.htm? $\mathrm{cn}=\mathrm{C} 01$. Accessed 13 Apr 2017.

NBOSC (National Bureau of Statistics of China). 2014. National data. http://data.stats.gov.cn/easyquery.htm? $\mathrm{cn}=\mathrm{C} 01$. Accessed 13 Apr 2017.

NBOSC (National Bureau of Statistics of China). 2015. China statistical yearbook 2015. http://www.stats.gov.cn/tjsj/ndsj/ 2015/indexch.htm. Accessed 13 Apr 2017.

SBOS (Statistical Bureau of Sichuan). 2014. Sichuan statistical yearbook 2014. http://www.sc.stats.gov.cn/tjcbw/tjnj/2014/ index.htm. Accessed 13 Apr 2017.

Sillah, F., H.J. Ho, and J.C. Chao. 2013. The use of oral rehydration salt in managing children under $5 y$ old with diarrhea in the Gambia: Knowledge, attitude, and practice. Nutrition 29(11-12): 1368-1373. 
SPHERE. 2011. The Sphere handbook: Humanitarian charter and minimum standards in humanitarian response. Southampton: Hobbs the Printers.

UNISDR (United Nations International Strategy for Disaster Reduction). 2015. The economic and human impact of disasters in the last 10 years. http://www.unisdr.org/files/42862_economichuma nimpact20052014unisdr.pdf. Accessed 13 Apr 2017.
WHO (World Health Organization). 2014. Flooding and communicable diseases fact sheet. http://www.who.int/hac/techguidance/ ems/flood_cds/en/index1.html. Accessed 14 Apr 2017.

World Factbook. 2016. China. https://www.cia.gov/library/publica tions/the-world-factbook/geos/ch.html. Accessed 13 Apr 2017. 